\title{
Model of integration of competencies in professionally-oriented education
}

\author{
Mikhail Rozin ${ }^{1, *}$, Valery Svechkarev ${ }^{1}$, Evgeny Nesmeyanov $^{2}$, Irina Ryabtseva ${ }^{2}$, Sergey \\ Yusov $^{3}$ \\ ${ }^{1}$ Southern Federal University, 105/42, Bolshaya Sadovaya str., Rostov-on-Don, Russia \\ ${ }^{2}$ Don State Technical University, 1, Gagarina, Rostov-on-Don, Russia \\ ${ }^{3}$ South-Russia Institute-Affiliation of the Russian Presidential Academy of National Economy and \\ Public Administration, 70, Pushkinskaya str., Rostov-on-Don, Russia
}

\begin{abstract}
It is noted that in higher professional education there is a global trend of the growing number of students combining the process of studying at the University with employment in the workplace in order to form a basis for their future professional and specialized career. Modern researches of the existing educational standards reveal the fact that there are practically no models meeting the needs of a new perspective on the organization of professionally-oriented training. It is suggested that the topological description on the basis of the graph theory, namely the cognitive model which has already been tested in the study of such problems in education should be used as a theoretical and methodological basis of the study. The cognitive model allows to involve the available model descriptions of educational processes, namely, structural-dynamic descriptions interpreted in this case as logical-semantic and causal. A multi-circuit cognitive model of professionally-oriented education based on the integration of competencies is proposed. The authors propose a multi-circuit cognitive model of professionally-oriented education based on the integration of competencies. The Central place in the model is given to the target chain of factors: Integration of competences $\rightarrow$ Professional competences $\rightarrow$ Educational and production process. This model helps transmit and synchronize signals across all model contours, continuously initialize the target model functioning, and analyze the achieved level of professional competencies in the integration process. It is on this axis that all four contours of the model are strung, which eliminates the loss of the target determination of the structure. The model implements the principle of professional orientation of education. Thus it is possible to balance the advantages of the educational competences received as a result of educational process, as well as the peculiarities of the production competences generated in manufacturing by means of their integration. Professional competencies in the model do not dominate, but rather are the result of continuous integration of both educational and industrial competencies.
\end{abstract}

* Corresponding author: mrozin@sfedu.ru 


\section{Introduction}

In recent years, in higher professional education, both in Russia and abroad, there has been an important global trend in the development of the opposition "educational process the employment of students during training". Thus, the authors of the study, the results of which are presented in [1], note that in Russia there is an increase in the number of students who combine the process of studying at the University with employment in the workplace in order to form the basis for their future professional and specialized career. The research conducted at universities in Germany, Italy, Norway and Spain, the results of which are presented in [2], led to similar conclusions. The authors not only state an increase in students' interest in employment related to the field of education, but also definitely argue for the formation of additional competitive advantages of graduates due to a higher probability of compliance with the competencies expected by the employer. But this effect is achieved only if the choice of parallel employment is coordinated with the sphere of training. The revealed tendency removes partly the confrontation between the student's time in the educational process and the need to work in the workplace. However, it assumes a professionally-oriented choice of employment of a University student, ensuring the coordination of these processes. The current state in the field of education does not yet initiate an active role of universities, shifting the solution of the problem of coordinated choice onto students whose secondary (industrial) employment is formed quite spontaneously [3]. Within the framework of the identified trend there is an urgent need to change the role of universities in the formation of professional competencies of future specialists [4], as well as to change the models and technologies for the formation of additional professional competencies $[5,6]$, and finally, change the organizational and infrastructure relations with the basic representatives of the labor market within the educational models of universities [7-9].

\section{Problem stating}

It is obvious that we should talk about understanding and reconsidering current educational models within the existing standards. This problem and the need to solve it, in particular, is indicated in the works $[10,11]$, which establish the fact of the practical lack of models that meet the new views on the organization of professionally oriented training. The work of the author's team [12] focuses the attention of subsequent researchers of this problem on the fundamental reliance on professional competence. The composition and structure of professional competencies of future specialists, largely stipulated by the employer, should determine the educational model.

First of all, we are talking about the adjustment of the basic competencies that define the educational process. And further, on the basis of the analysis of the formed educational process in terms of its compliance to professional competences of the future expert, to introduce production and practice-oriented procedures into the educational process i.e. to form educational model on the basis of already shaped professional competences. The development and research of such competence-based educational models is covered by a wide range of papers, for example [5-9, 13, 14]. The disadvantages of these and similar works are associated with their principal orientation to specific professional competencies, and the construction of the educational process, based on this specificity. We believe that it is necessary (as has already happened with the opposition "educational process employment of students during training") to remove the very possibility of dominance of any competencies in the development of the educational process. We propose to develop an educational model based on the integration of competencies, achieving on this path such an integrative effect, which will determine the composition and structure of professional 
competencies of future specialists.

\section{Methods of Research}

As a theoretical and methodological basis of this article we use the description which has already been tested in the study of such problems in education [15], a topological description based on graph theory, namely a cognitive model [16].

The cognitive model in principle allows to rely in the process of research on the amount of knowledge available in the scientific literature for the analysis of the observed situation. In relation to the present situation, we consider the available model descriptions of educational processes, in particular, structural-dynamic descriptions, interpreted in this case, as logical-semantic and causal. The cognitive model allows us to present a holistic view of the implemented educational process through its graphic image filled with meanings and dynamics of causal relations.

\section{Case Study and their Analysis}

Thus, the cognitive model of the educational process with the integration of competencies is designed not to resolve the contradictions of educational and production processes, but, using the resources and capabilities of each of them, to form a single structure of relations. As one of the most important aspects in cognitive modeling is the goal, namely, model building, with a focus on achieving specific goals, and composition of model elements and connections (relations) between them are determined depending on the purpose of the study. Thus, the cognitive model of the educational process with the integration of competencies is designed not to resolve the contradictions of educational and production processes, but, using the resources and capabilities of each of them, to form a single structure of relations. As one of the most important aspects in cognitive modeling is the goal-setting, namely, the construction of a model with a focus on achieving a specific goal, and the composition of the elements of the model and the relationship (relationship) between them are determined depending on the purpose of the study.

Only the objectives of the study in a specific problem situation determine the choice of the most useful and effective prototype of the model of the social system. In this case, the aim is to form an educational process with the integration of competencies.

We interpret the goal as a Central target factor called Competence Integration. The role of the target factor The Competence Integration as a system-forming one determines the goal-setting for other factors and connections of the model, determines the target structure of the model as a whole. Target factor Competence Integration occupies the central key place in the model, it integrates the causes, because changes take place in each "causal" factor belonging to the educational or production processes. At the same time, it decomposes the consequences, because changes in the key factor cause subsequent changes in the incident key factors of the corresponding processes. Therefore, further analysis of the characteristic features of the cognitive model as a deterministic target structure switches our attention to the semantic and causal relations, built in accordance with the targets and a special place in the structure of the model of the target factor. The search for General semantic content assumes an appropriate level of structural detail. Such a basic structure is a two-circuit cognitive model with a target factor in the form of a knot of intersection of contours [15]. Indeed, the semantic content of the model assumes the joint functioning of the educational process and the production process, and their semantic and causal linkage can be carried out through the Central target factor of competence Integration.

This is what we see in figure 1. - the core of the cognitive model of the educational 
process with integration ration of competences. The core includes two circuits. The first is the educational circuit $(\mathrm{OK})$. It is formed by causally related factors Integration of competences $\rightarrow$ Skills $\rightarrow$ Educational process $\rightarrow$ Educational competences $\rightarrow$ integration of competences. All factors included in the contour form a simple path, i.e. such a directed sequence of vertices in which all vertices are different except the first and last. This vertex is the target factor. Similarly, the second circuit is the production circuit. It includes causally related factors Integration of competencies $\rightarrow$ Knowledge $\rightarrow$ production Process $\rightarrow$ Production competencies $\rightarrow$ integration of competencies. Each of the presented circuits implements a positive feedback, i.e. stimulates self-change states of the factors in a given direction. For example, if the integration of competencies is successful, then Skills are improved, which leads to a more thorough assimilation of the Educational process, Educational competencies are improved, which increase the success of the integration of competencies. Similarly, the logic of development is built for the second circuit.

For example, if the integration of competencies is successful, then Knowledge is increased, which improves the implementation of the Production process, Production competencies are strengthened, which increase the success of the integration of competencies. Positive feedbacks provide the necessary "amplification" trends for integration development. Increasing the value of any of the factors immediately initiates the strengthening of all others. The unique position of the target factor integration of competencies, namely, the inclusion in both circuits (confirming its consistency), allows you to translate the gain achieved in one of the circuits to the second circuit and back, while "feeding" from each circuit. Classical illustration of the nodal model of integration of causes and decomposition of effects.

Hence, another important aspect of translation through the nodal factor is the Integration of competencies into the corresponding amplification effects circuits. For example, the translation of knowledge generated by the strengthening of Educational competencies in the PC circuit, or skills acquired in the PC circuit in the factor of Production competence in the OK circuit to enhance the functioning of the Educational process.



Fig. 1. Cognitive model of educational process with integration of competences. 
However, this kind of developing two-circuit model with mutually translatable positive connections has a latent flaw, concealing risks of implementation. It consists in the fact that a factor is needed that continuously initiates the signal of development. None of the factors of the two-circuit model is such. The absence of an initialization signal can suspend the development process or start its dismantling.

Therefore, it is proposed to supplement the model with two more factors, namely, Professional competence and Training and Production process (see Fig.1). These two factors form two additional circuits in the model together with the core. Each of the newly formed circuits implements a scheme of adaptation of educational (AO) and industrial (AP) processes and represents a "chain of initialization" of competence Integration. Let's see how it works.

The requirement to strengthen (change, expand, etc.) professional competencies, for example, on the part of the employer, is implemented through a corresponding change in the Educational and production process. The factor of Educational and production process is also a node and, accordingly, decomposes the need for changes synchronously in both basic (nuclear) factors-the Educational process and the production Process. Thus, each of the already considered contours of the model core is started. Since these factors, the Educational process and the production Process have also become nodal and now integrate signals both within the circuit itself (from the factor preceding in the circuit) and coming from the additional circuit from the factor of the Educational and Production process. The structure of the first additional contour of adaptation of educational process (AU) includes causally related factors Integration of competences $\rightarrow$ Professional competences $\rightarrow$ Educational and production process $\rightarrow$ Educational process $\rightarrow$ Educational competences $\rightarrow$ integration of competences. Similarly, the second circuit is the production process adaptation circuit (A P). It includes causally related factors Integration of competencies $\rightarrow$ Professional competencies $\rightarrow$ Training and production process $\rightarrow$ production Process $\rightarrow$ Production competencies $\rightarrow$ Integration of competencies.

Three factors form the chain of competence Integration $\rightarrow$ Professional competence $\rightarrow$ Training and production process and are included in both additional circuits. But at the same time, through the competence Integration factor, the chain is connected to the two contours of the model core. And, if the competence Integration factor organizes the transmission of signals between the core circuits (OK and PC), then the Training and production process factor controls the signals in the adaptation circuits (AO and AP). The Central factor in this axis is Professional competence. Through it, the continuous initialization of the target functioning of the model is carried out by influencing the factor of the Educational and production process. It receives and analyzes the achieved level of professional competencies in the process of competence integration. The information obtained will again be used to manage the adaptation of educational and production processes. It is on this axis that all four contours of the model are strung, which eliminates the loss of the target determination of the structure.

Finally, another important aspect of the proposed model is the fundamental reliance on professional competencies [12]. The model implements the principle of professional orientation of education. Thus it is possible to balance advantages of the educational competences received as a result of educational process, and features of the production competences formed on production, by their integration. Professional competencies in the model do not dominate, but are the result of this integration. This allows us to count on "the formation of additional competitive advantages of graduates due to the higher probability of compliance with the competencies expected by the employer" [2].

Thus, in the proposed model, professional competencies develop not only and not so much within the educational process, but are the result of continuous integration of both educational and industrial competencies. 
Hence, the name of the educational model - a model based on the integration of competencies. The graduate is a carrier of competencies, and it is fundamentally important throughout the professionally-oriented educational process to ensure systematic replenishment and integration of these competencies. It is obvious that the proposed model assumes a somewhat expanded view of the standards of the organization of professionallyoriented educational process. At the same time, the model is quite versatile. It can be used within a University only, for example, if it is a research University, to train scientists and highly qualified professionals. On the basis of the model, temporary (contractual) University - industrial enterprise associations can be formed to prepare graduates for a specific production. But the most expedient in our opinion is the use of the model in the framework of educational, scientific and industrial complexes, where it is possible to achieve a balanced integration of competencies.

\section{Conclusion}

1. In recent years, there has been an important global trend in higher professional education in the form of educational process-employment of students in training towards an increase in the number of students combining the process of studying at the University with employment in the workplace in order to form a basis for future professional and specialized career. There is a need to change the role of universities in the formation of professional competencies of future specialists within the framework of the identified trend.

2. Modern researches of the existing educational standards reveal the fact of practical absence of the models meeting the new views on the organization of professionallyoriented training. The composition and structure of professional competencies of future specialists, determined largely by the employer, should determine the educational model.

3. As a theoretical and methodological basis of the study, it is advisable to use the cognitive model, which has already been tested in the study of such problems in the formation of a topological description on the basis of graph theory. The latter essentially allows to involve the available model descriptions of educational processes, in particular, structural-dynamic descriptions interpreted in this case as logical-semantic and causal.

4. We propose a multi-circuit cognitive model of professionally-oriented education based on the integration of competencies. The Central place in the model is given to the target chain of factors Integration of competences $\rightarrow$ Professional competences $\rightarrow$ Educational and Production process. Through it, signals are broadcast and synchronized along all the contours of the model, continuous initialization of the target functioning of the model, analysis of the achieved level of professional competencies in the process of integration. It is on this axis that all four contours of the model are strung, which eliminates the loss of the target determination of the structure.

5. The model implements the principle of professional orientation of education. Thus it is possible to balance the advantages of the educational competences received as a result of educational process, and peculiarities of production competences, formed in the production, through their integration. Professional competencies in the model do not dominate, but rather are the result of this integration. Thus, in the proposed model, professional competencies develop not only and not so much within the educational process, but are the result of continuous integration of both educational and industrial competencies.

\section{Acknowledgements}

The funding for the study is received from the Southern Federal University (grant VnGr07/2017-20). 


\section{References}

1. V.I. Filonenko, L.S. Skachkova, Yu.V. Filonenko, Sotsiologicheskie issledovaniya 9, 135-140 (2018) DOI: 10.31857/S013216250001970-0

2. G. Passaretta, M. Triventi, International Journal of Comparative Sociology 56(3-4), 232-253 (2015)

3. A.M. Tikhomirova, O.V. Myltasova, Moskovskiy ekonomicheskiy zhurnal 4, 467-476 (2018)

4. A.Z. Gilmanov, S.O. Kovalenko, Sotsiologicheskie issledovaniya 1, 134-135 (2015)

5. E.V. Karavaeva, O.V. Vorobieva, V.P. Tyshkevich, Higher Education in Russia 27(4), 33-47 (2018)

6. V.Yu. Stromov, P.V. Sysoyev, V.V. Zavyalov, Higher Education in Russia 27(5), 2029 (2018)

7. E.Ya. Kogan, N.Yu. Postalyuk, T.G. Kuteinitsyna, Higher Education in Russia 28(7), 9-18 (2019) DOI: https://doi.org/10.31992/0869-3617-2019-28-7-9-18.

8. V.M. Anikin, B.N. Poizner, E.A. Sosnin, Higher education in Russia 28(3), 35-49 (2019) DOI: https://doi.org/10.31992/0869-3617-2019-28-3-35-49

9. V.S. Khamidulin, Higher Education in Russia 29(1), 135-149 (2020) DOI: https://doi.org/10.31992/0869-3617-2020-29-1-135-149

10. J. Baughman, Student professional development: Competency-based learning and assessment in an undergraduate industrial technology course. Graduate Theses and Dissertations (2012) https://lib.dr.iastate.edu/etd/12592

11. E. Abes, S. Jones, M. McEwen, Journal of College Student Development 58(1), 1-22 (2007)

12. A. Makulova, G. Alimzhanova, Z. Bekturganova, Z. Umirzakova, L. Makulova, K. Karymbayeva, International Education Studies 8(8), 183-192 (2015)

13. K. Bauer, Y. Bai, Procedia - Social and Behavioral Sciences 174, 705-710 (2015)

14. L.V. Tarasenko, M.D. Rosin, V.P. Svechkarev, K.A. Avanesyan, Media Education (Mediaobrazovanie) 58(4), 130-137 (2018) http://ejournal53.com/journals_n/1544017213.pdf

15. L. Tarasenko, M. Rosin, V. Svechkarev, Media Education (Mediaobrazovanie) 59(4), 588-593 (2019) http://ejournal53.com/journals_n/1575379969.pdf

16. R. Axelrod, The Structure of Decision: Cognitive Maps of Political Elites (Princeton University Press, 1976) 